\title{
Influence of the knot position on the union of the greater trochanter after bipolar hip arthroplasty via the modified Dall approach: a prospective non-randomized study
}

Masanao Kataoka ${ }^{1}$, Hiroshi Fujita ${ }^{1 *}$, Hiroaki Hara ${ }^{2}$, Hideto Harada ${ }^{1}$, Yuki Okutani ${ }^{1}$ and Yoshiki Murotani ${ }^{1}$

\begin{abstract}
Background: In our institute, all elderly patients with displaced femoral neck fracture were treated with cemented bipolar hemiarthroplasty (BHA) using the modified Dall approach. To our knowledge, there are no reports on the knot position of the greater trochanter reattachment. The aim of this study was to determine influence of two knot positions (anterior or posterior) on the complications of the greater trochanter.

Methods: This is a prospective non-randomized study conducted on 95 elderly patients (95 hips) from September 2013 to December 2017. The knot position was changed from anterior to posterior alternately. The X-ray images obtained immediately after the operation were compared with those obtained at 3 months postoperatively; thereafter, the status of the greater trochanter was classified into three types: type A, no apparent shifting and fracture; type C, over 1-mm shifting of the fragment; and type F, fracture of the greater trochanter.

Results: Regarding age at operation, sex, BMI, size of the greater trochanteric fragment, stem type, and surgeon, there was no significant difference between two groups. In the anterior group, 34 hips (72.3\%), 5 hips (10.6\%), and 8 hips (17.0\%) were classified under type A, C, and F, respectively. In the posterior group, 44 hips (91.7\%), 1 hip (2.1\%), and 3 hips (6.3\%) were classified under type A, C, and F, respectively. There were significantly fewer greater trochanteric complications in the posterior group.
\end{abstract}

Conclusions: The posterior knot position improved the union of the greater trochanter after BHA compared with the anterior knot position.

Trial registration: We had approved IRB at our hospital clinical research review committee. Retrospectively registered.

Keywords: Bipolar hemiarthroplasty, Modified Dall approach, Knot position, Complications of the greater trochanter

\footnotetext{
* Correspondence: hfshoot@gmail.com

${ }^{1}$ Institute for Joint Replacement, Department of Orthopedic Surgery, Kyoto Katsura Hospital, Yamada-hirao-cho 17, Nishikyo-ku, Kyoto 615-8256, Japan

Full list of author information is available at the end of the article
}

C C The Author(s). 2021 Open Access This article is licensed under a Creative Commons Attribution 4.0 International License, which permits use, sharing, adaptation, distribution and reproduction in any medium or format, as long as you give appropriate credit to the original author(s) and the source, provide a link to the Creative Commons licence, and indicate if changes were made. The images or other third party material in this article are included in the article's Creative Commons licence, unless indicated otherwise in a credit line to the material. If material is not included in the article's Creative Commons licence and your intended use is not permitted by statutory regulation or exceeds the permitted use, you will need to obtain permission directly from the copyright holder. To view a copy of this licence, visit http://creativecommons.org/licenses/by/4.0/. The Creative Commons Public Domain Dedication waiver (http://creativecommons.org/publicdomain/zero/1.0/) applies to the data made available in this article, unless otherwise stated in a credit line to the data. 


\section{Background}

According to the National Institute for Health and Care Excellence guidelines [1], replacement arthroplasty (total hip replacement or hemiarthroplasty) is recommended to patients with displaced intracapsular hip fracture.

There are three main categories of surgical approaches to hip arthroplasty: lateral approaches (LAs), posterior approaches (PAs), and anterior approaches (AAs). A recent meta-analysis [2] showed that PAs are associated with a higher risk of dislocation and re-operation than AAs and LAs. In our country LAs were relatively widely used and several good results were reported [3, 4].

In our institute, all elderly patients who had displaced femoral neck fracture were treated with cemented bipolar hemiarthroplasty (BHA) using the modified Dall approach [5], in which the greater trochanter was cut partially with the gluteus medius muscle. The modified Dall approach is a superior approach in that it can provide sufficient visualization during total hip arthroplasty (THA) or BHA. This approach can be used in cases requiring bone grafting because of acetabular dysplasia and can avoid excessive detachment of the soft tissues. However, this approach requires cutting apart of the greater trochanter. Therefore, it is necessary to take measures to prevent complications around the greater trochanter. Dislocation of the fragment may lead to nonunion, and fragility of the posterior part of the greater trochanter may lead to fracture of the tip. In past procedures performed in our institute using the original Dall method, in which non-absorbable polyester sutures (Ethibond, Johnson \& Johnson K.K., Tokyo, Japan) were passed through the greater trochanter, there were many complications observed. Two studies previously reported that ultra-high molecular weight polyethylene (UHMWPE) fiber cables yielded a sufficient degree of fixation equal to that in metal wires in spinal fusion surgery $[6,7]$. Therefore, the fixation materials were changed from non-absorbable polyester sutures to UHMWPE fiber cables. The UHMWPE fiber cables were passed around the femur instead of through the greater trochanter, and the gluteus minimus tendon was partially cut apart, which enabled the reduction of the traction force against the greater trochanter. The trochanteric fragment was reattached at the original position using two UHMWPE fiber cables $(3.0 \mathrm{~mm}$ in width) (NESPLON Cable System, Alfresa Pharma Co., Osaka, Japan). The cables were tightened around the femur using an anterior loop and were tied up using a double-loop sliding knot. However, there were some cases in which the fragments were displaced or fracture occurred at the greater trochanter.

We thought that knot position was important because knots caused local irritation and stimulated inflammation around the greater trochanter. To our knowledge, there was no reports on the knot position of the greater trochanter reattachment. There were two knot positions: anterior and posterior to the fragment. The aim of this study was to determine the influence of these two knot positions on the complications of the greater trochanter, and which knot position was clinically superior.

\section{Methods}

This study was a prospective non-randomized study conducted on 95 elderly patients (95 hips) with displaced femoral neck fracture who were treated with cemented BHA in our institute from September 2013 to December 2017. This study adhered to CONSORT guidelines. Sample size was determined that $\mathrm{p} 1=0.3, \mathrm{p} 2=0.6, \alpha=$ $0.05,1-\beta=0.8$ resulted 42 . Inclusion criteria were diagnosed of displaced femoral neck fracture, then 114 patients (114 hips) were met the criteria. Exclusion criteria were patients who had osteoarthritis or dysplasia (Sharp angle over 45 degrees) of the same side of fracture and patients who had no tolerance of surgery. Six patients (6 hips) met the former exclusion criteria, then they were treated with cemented THA. Thirteen patients (13 hips) met the latter exclusion criteria, then they were treated conservative. The knot position was changed from anterior (Fig. 1) to posterior (Fig. 2) alternately, and the surgeon did not know which knot position to adopt until just before the knotting. A third party other than the doctor or nurse assigned the knot position. The anterior position was used in 47 hips and the posterior position in 48 hips. This study was approved by our institutional review board, and Informed consent was obtained from each patient.

All operations were performed using the modified Dall approach. A chisel was used to cut the greater trochanter partially. The fragment thickness was maintained at $10 \mathrm{~mm}$, and the fragment was not cut through entirely. In this manner, the osteotomy surface had a ramp, which prevented the fragment from shifting anteriorly. The fragment of the greater trochanter was measured using Vernier calipers: length (maximum cranio-caudal length), width (maximum antero-posterior length), and thickness before the fragment was reattached. The estimated volume of the fragment was calculated as follows: length $\times$ width $\times$ thickness.

In order to pull the fragment $15 \mathrm{~mm}$ posterior to the original position, the tendinous portion of the gluteus minimus was cut before reattaching. For the fixation method, two 3.0-mm-width UHMWPE fiber cables were pathed around the femur using anterior loops; thereafter, the cables were tied up using a double-loop sliding knot. The gun tensioning system (Tightning Gun TGL, Alfresa Pharma Co., Osaka, Japan) at more than $20 \mathrm{~kg}$ was used, and the cables were later tied four times by hand and 


\section{a}

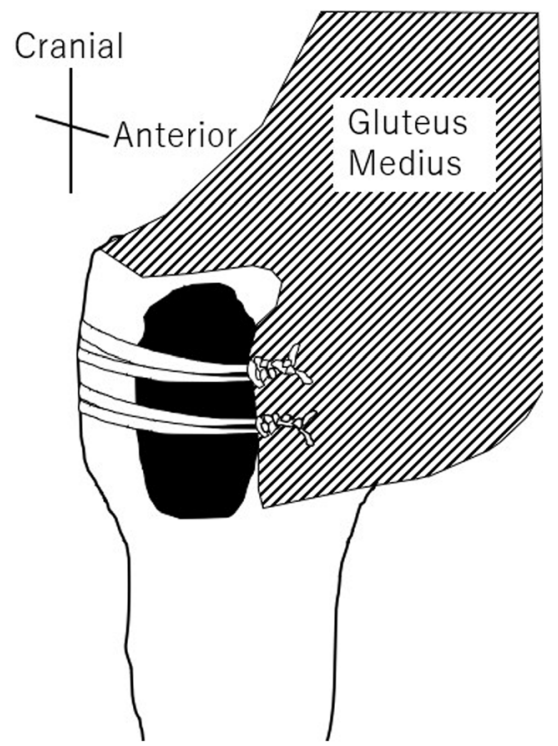

b

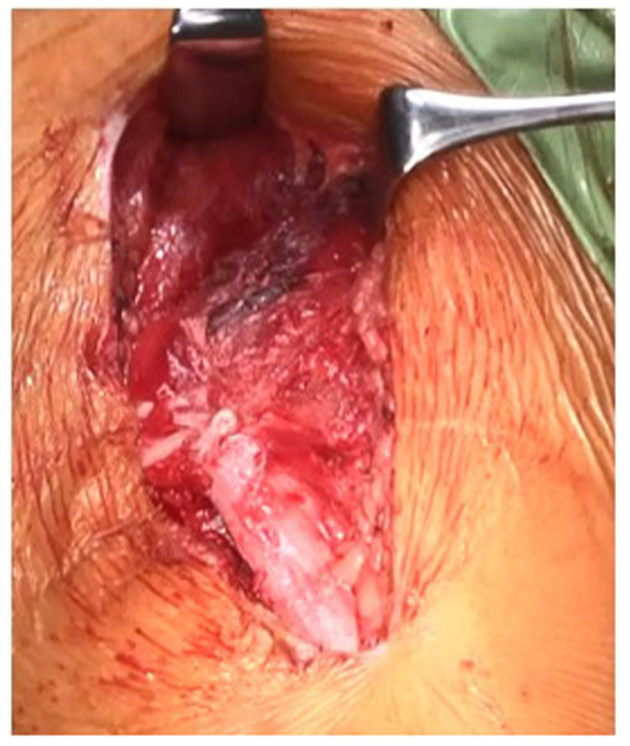

Fig. $\mathbf{1}$ a is schema of the anterior knot position of the right femoral hip; $\mathbf{b}$ is an operative photograph of a case of anterior knot group

finally tied once using the gun tensioning system at more than $20 \mathrm{~kg}$.

Eleven Exeter stems (Stryker Orthopedics, Mahwah, New Jersey) and 84 SC stems (KYOCERA Medical, Osaka, Japan) were used. Exeter stem is the cemented polished double-tapered stem, and it has excellent outcomes in Japan $[8,9]$. SC stem is the cemented polished triple-tapered stem. All stems were implanted with two packs of Simplex P bone cement (Stryker Orthopedics,
Mahwah, New Jersey) and using the interface bioactive bone cement technique [10-12].

The antero-posterior supine-positioned X-ray images obtained immediately after the operation were compared with those obtained at 3 months postoperatively, without informing the surgeons, patients, physical therapists, and radiologists which knot positions were applied. Osteotomy healing or union of the greater trochanter was then classified into three types: type A, no apparent shifting

\section{a}

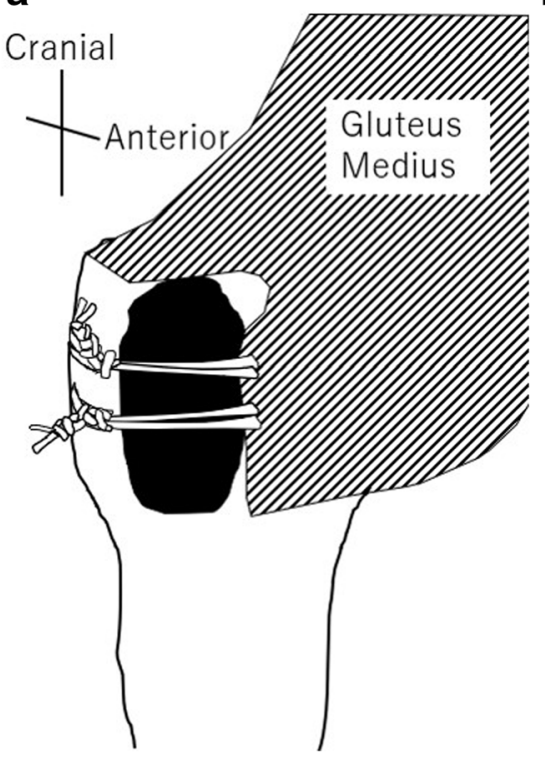

b



Fig. $\mathbf{2}$ a is schema of the posterior knot position of the right femoral hip; $\mathbf{b}$ is an operative photograph of a case of posterior knot group 
of the trochanteric fragment and fracture of the greater trochanter; type $\mathrm{C}$ (Fig. 3), over 1-mm shifting of the trochanteric fragment; and type F (Fig. 4), fracture of the greater trochanter. Three doctors $(\mathrm{HH}, \mathrm{MK}$, and $\mathrm{HF})$ classified the status of the greater trochanter. Disagreements were resolved by consultation. The patients' age at operation, sex, and body mass index (BMI); size of the greater trochanteric fragment; type of the stem; and experience of the surgeon (surgeon A: 20 years of experience, surgeon B: 15 years of experience; "others", C: 5 years of experience and D: 15 years of experience) were analyzed using the t-test and chi-square test. C and D performed operations in fewer than five hips; thus, they were classified as "others".

All analyses were performed using Statcel 4 (OMS Publ., Tokyo, Japan), which is an add-in software of Excel (Microsoft, Redmond, Washington). The statistical significance level was set at a value of $<5 \%$.

\section{Results}

Regarding age at operation, sex, BMI, size of the greater trochanteric fragment, estimated volume of the fragment, type of the stem, and surgeon, there was no significant difference between the anterior and posterior groups (Table 1).

In the anterior group, 34 hips (72.3\%), 5 hips (10.6\%), and 8 hips (17.0\%) were classified under type A, type C,

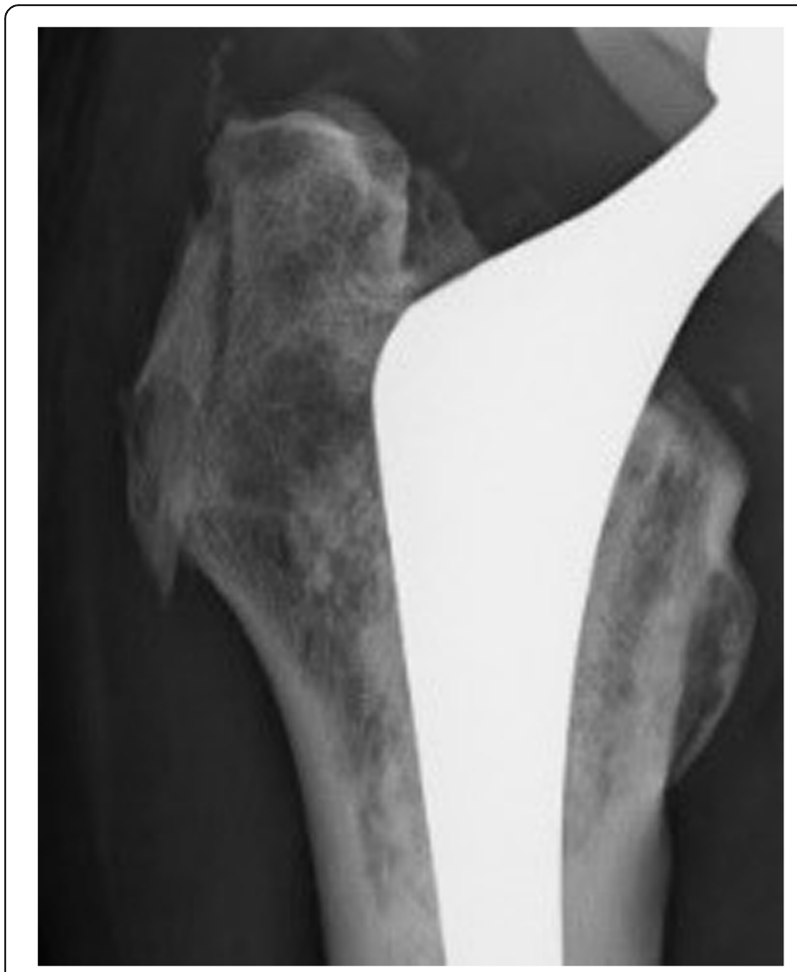

Fig. 3 A case of type C. The trochanteric fragment was shifted distally over $1 \mathrm{~mm}$ at 3 months postoperatively

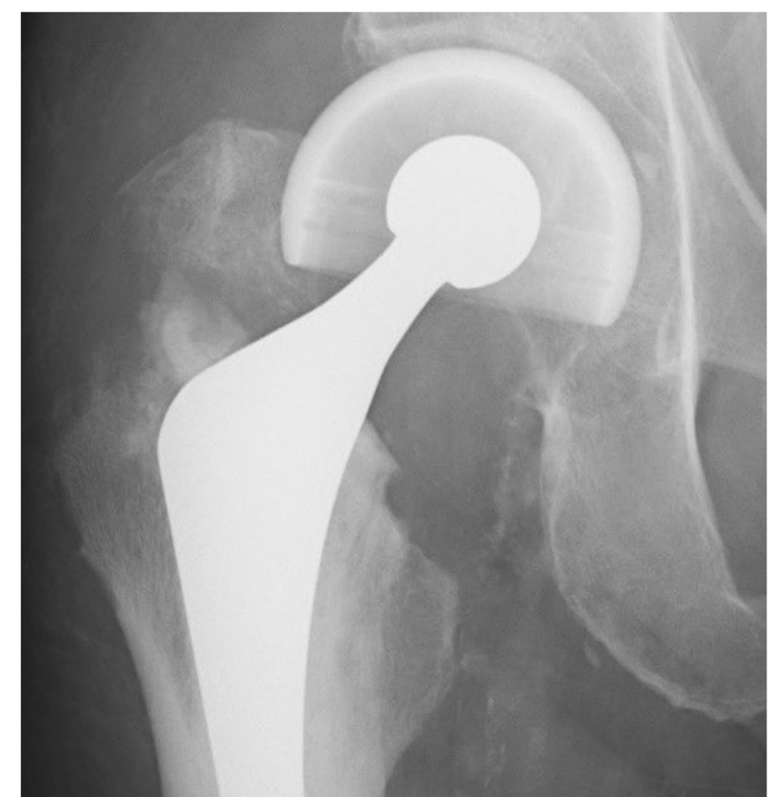

Fig. 4 A case of type F. Fracture was occurred at the greater trochanter at 3 months postoperatively

and type F, respectively. In the posterior group, 44 hips (91.7\%), 1 hip (2.1\%), and 3 hips (6.3\%) were classified under type A, type $\mathrm{C}$, and type $\mathrm{F}$, respectively. A significant difference was found in type A between the two groups. A significant difference was also found in the BMI $(p=0.047)$ and suturing position $(p=0.013)$ between type A and type $\mathrm{C}+\mathrm{F}$ (Table 2 ).

\section{Discussion}

There are some reports of patients who had displaced femoral neck fracture and were treated with BHA via the modified Dall approach [13]; however, to our knowledge, there is no report on greater trochanteric complications and size of the greater trochanteric fragment. A hypothesis was that the fragment was larger, so as type $\mathrm{F}$ was increased, and the fragment was smaller, so as type $\mathrm{C}$ was increased. There was no statistically significant difference for complications with the size of the greater trochanteric fragment. However, knot position greatly influenced complications of the greater trochanter.

Oe et al. [3] reported that the incidence of greater trochanteric complications was $7.9 \%$ (37/466 hips) in their THA cases via the modified Dall approach using two UHMWPE fiber cables (applied when the greater trochanteric fragment was reattached). Kuroda et al. [4] also reported that the incidence of greater trochanteric complications was $5.0 \%$ (3/60 hips) in their THA cases via the modified Mostardi approach using two UHMPE fiber cables. In the present study, there were only a few greater trochanteric shifting cases (type C; 6.3\%; 6/95 hips). The incidence of greater trochanteric fractures 
Table 1 Patient characteristics

\begin{tabular}{|c|c|c|c|}
\hline Parameter & Anterior group & Posterior group & $p$ value \\
\hline Number of hips & 47 & 48 & \\
\hline Age at operation; years old (range) & $82.4 \pm 7.0(69-95)$ & $82.6 \pm 7.9(62-98)$ & 0.89 \\
\hline Sex, male:female & $14: 33$ & 18:30 & 0.43 \\
\hline Body mass index; kg/m2 (range) & $20.1 \pm 3.7(13.4-27.7)$ & $18.9 \pm 3.4(12.2-28.3)$ & 0.10 \\
\hline \multicolumn{4}{|c|}{ Size of the greater trochanteric fragment } \\
\hline length; mm (range) & $33.2 \pm 5.7(23-45)$ & $33.3 \pm 5.3(22-45)$ & 0.93 \\
\hline width; mm (range) & $21.7 \pm 4.1(14-34)$ & $21.4 \pm 4.0(14-30)$ & 0.76 \\
\hline thickness; mm (range) & $8.9 \pm 1.8(5-14)$ & $8.8 \pm 1.9(5-12)$ & 0.81 \\
\hline estimated volume; mm3 (range) & $6810 \pm 3547(1820-17,640)$ & $6706 \pm 3213(2030-13,766)$ & 0.89 \\
\hline Type of the stem & & & 0.38 \\
\hline Exeter & $4(8.5 \%)$ & $6(12.5 \%)$ & \\
\hline SC & $43(91.5 \%)$ & $42(87.5 \%)$ & \\
\hline Surgeon & & & 0.31 \\
\hline A & $26(55.3 \%)$ & $30(62.5 \%)$ & \\
\hline B & $16(34.0 \%)$ & $10(20.8 \%)$ & \\
\hline Others & $5(10.6 \%)$ & $8(16.7 \%)$ & \\
\hline Type of the greater trochanter & & & $0.045^{*}$ \\
\hline Type A & $34(72.3 \%)$ & $44(91.7 \%)$ & \\
\hline Type C & $5(10.6 \%)$ & $1(2.1 \%)$ & \\
\hline Type F & 8 (17.0\%) & $3(6.3 \%)$ & \\
\hline
\end{tabular}

mean \pm standard deviation

*means less than $5 \%$

Table 2 Comparison between type A and C + F

\begin{tabular}{llll}
\hline Parameter & Type A & Type $\mathbf{C + F}$ & $\boldsymbol{p}$ value \\
\hline Number of hips & 78 & 17 & \\
Age at operation; years old & $82.7 \pm 7.4$ & $81.7 \pm 7.5$ & 0.60 \\
Sex, male:female & $28: 50$ & $4: 13$ & 0.25 \\
Body mass index; kg/m2 & $19.2 \pm 3.6$ & $21.0 \pm 3.2$ & $0.047^{*}$ \\
Size of the greater trochanteric fragment & & \\
$\quad$ length; mm & $33.2 \pm 5.8$ & $33.4 \pm 4.2$ & 0.89 \\
width; mm & $21.6 \pm 4.0$ & $21.3 \pm 4.3$ & 0.83 \\
thickness; mm & $8.9 \pm 1.8$ & $8.5 \pm 2.0$ & 0.36 \\
Type of the stem & & & 0.43 \\
$\quad$ Exeter & $9(11.5 \%)$ & $1(5.9 \%)$ & \\
SC & $69(88.5 \%)$ & $16(94.1 \%)$ & \\
Surgeon & & & 0.25 \\
A & $49(62.8 \%)$ & $7(41.2 \%)$ & \\
B & $19(24.4 \%)$ & $7(41.2 \%)$ & \\
Others & $10(12.8 \%)$ & $3(17.6 \%)$ & \\
Knot position & & & \\
Anterior & $34(43.6 \%)$ & $13(76.5 \%)$ & \\
Posterior & $44(56.4 \%)$ & $4(23.5 \%)$ & \\
\hline
\end{tabular}

mean \pm standard deviation

* means less than $5 \%$ (type F) was $11.6 \%$ (11/95 hips) and almost identical to previous reports (Table 3). When the anterior and posterior knot outcomes were compared with previous findings, the outcome of the anterior knot was worse than past reports [3, 4]; however, the outcome of the posterior knot was identical to that reported by Oe et al. [3], although the patients were older and had femoral neck fracture. As the present study included patients with displaced femoral neck fracture and they were older, bone weakness was expected; thus, the incidence of greater trochanteric complications (greater trochanteric fracture in particular) were expected to be high. However, the result was equal to that of THA cases; thus, there was a confounding factor other than bone density.

Statistically, the age at operation, sex, size of the greater trochanteric fragment, type of the stem, and experience of the surgeon did not influence the greater trochanteric complications in the present study. In their THA cases performed via the modified Dall approach, Oe et al. [3] reported that the patients' age and experience of the surgeon were risk factors for the complications of the greater trochanter. In the present study, the BMI and knot position were the risk factors (Table 2).

The incidence of greater trochanteric complications was significantly lower in the posterior group than in the anterior group. To our knowledge, no other institutions 
Table 3 The ratio of the greater trochanteric complications

\begin{tabular}{llllll}
\hline Parameters & $\begin{array}{l}\text { Present study } \\
\text { Whole group }\end{array}$ & $\begin{array}{l}\text { Present study } \\
\text { Anterior group }\end{array}$ & $\begin{array}{l}\text { Present study } \\
\text { Posterior group }\end{array}$ & Oe et al. & Kuroda et al. \\
\hline Mean age at opertion; years old & $82.5 \pm 7.4$ & $82.4 \pm 7.0$ & $82.6 \pm 7.9$ & $64 \pm$ uncertain & $59.4 \pm 12.2$ \\
Number of hips & 95 & 47 & 48 & 466 & 60 \\
Surgical form & BHA & BHA & BHA & THA & THA \\
Approach & Modified Dall & Modified Dall & Modified Dall & Modified Dall Modified Mostardi \\
Knot position & Anterior+Posterior & Anterior & Posterior & uncertain & uncertain \\
All greater trochanteric complications & $17.9 \%$ & $27.6 \%$ & $8.3 \%$ & $7.9 \%$ & uncertain \\
Migration of the fragment & $6.3 \%$ & $10.6 \%$ & $2.1 \%$ & uncertain \\
Fracture of the greater trochanter & $11.6 \%$ & $17.0 \%$ & $6.3 \%$ & uncertain & uncertain \\
\hline
\end{tabular}

reported the difference in the knot position of the greater trochanteric fragment.

Although we could not examine such herein, the activity of daily living and strength of the gluteus medius muscle before the injury may influence the trochanteric complications; further examinations are necessary for THA cases.

The gluteus medius muscle can pull the fragment of the greater trochanter forward horizontally to the osteotomy surface; however, it is thought that the fragment digs into the ramp on the surface, which prevents the fragment from shifting anteriorly. When the knot was anteriorly positioned, the contact pressure with the tensor fascia lata muscle increased during external rotation, and it was thought that patients felt pain or discomfort and tended to assume the internal rotation position to avoid stimulation (Fig. 5). When the thighs assume the internal rotation position, the gluteus medius and gluteus minimus muscles contract and therefore pull the fragment horizontally to the osteotomy surface, causing the fragment to shift anteriorly. In addition, as the

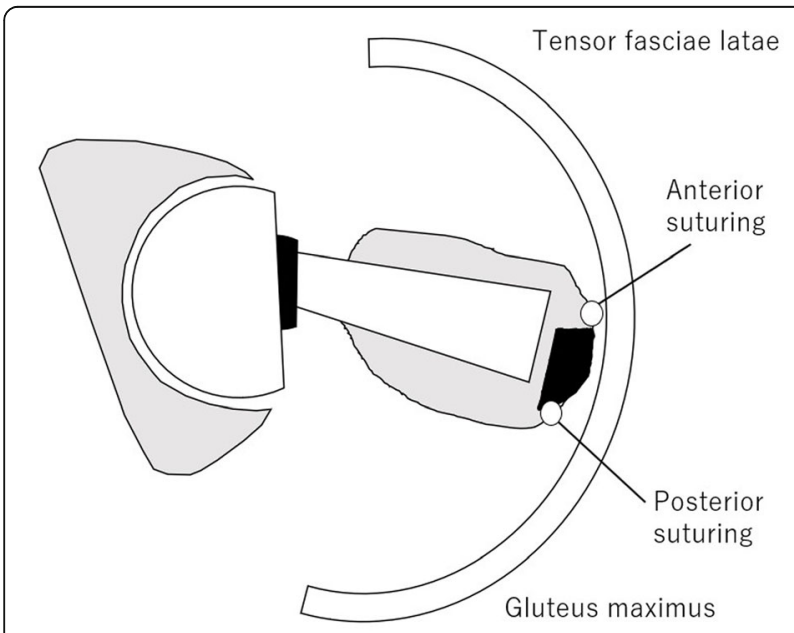

Fig. 5 Relationship between the knot positions and muscles; the schema of the right hip is reflected from the top external rotation muscles become hyper-tense, the power to pull backwards increases, resulting in bone fracture at the non-cut area of the greater trochanter. Tip fracture occurs because the piriformis muscle and external rotator muscles, which lack plasticity, pull the tip of the greater trochanter strongly when the thighs assume the internal rotation position.

The limitations of the present study was that it was not a randomized study, it included relatively few cases, the follow-up period was short, it lacked data on clinical scores and functional outcomes, and the SC stem and Exeter stem were inserted depending on the surgeon's discretion.

\section{Conclusion}

The posterior knot positioning demonstrated better results than the anterior one. The present study findings are meaningful in that they may help improve the outcomes of the Dall approach.

\section{Abbreviations}

LAs: Lateral approaches; PAs: Posterior approaches; AAs: Anterior approaches; BHA: Bipolar hemiarthroplasty; THA: Total hip arthroplasty; UHMWPE: Ultrahigh molecular weight polyethylene; BMI: Body mass index

\section{Acknowledgements \\ Not applicable.}

\section{Authors' contributions}

All authors contributed to the study conception and design. Material preparation, data collection and analysis were performed by $\mathrm{MK}, \mathrm{HF}$ and $\mathrm{HH}$. The first draft of the manuscript was written by MK and all authors commented on previous versions of the manuscript. All authors read and approved the final manuscript.

Funding

There was no funding about this study.

\section{Availability of data and materials}

The datasets analyzed during the study are available from the corresponding author upon reasonable request.

\section{Ethics approval and consent to participate}

The Kyoto Katsura Hospital Clinical Research Review Committee approved this clinical research on November 14, 2019 No.668. Retrospectively registered. The informed consent obtained from study participants was written. 


\section{Consent for publication}

Not applicable.

\section{Competing interests}

The authors declare that they have no competing interests.

\section{Author details}

'Institute for Joint Replacement, Department of Orthopedic Surgery, Kyoto Katsura Hospital, Yamada-hirao-cho 17, Nishikyo-ku, Kyoto 615-8256, Japan. ${ }^{2}$ Department of Rehabilitation, Kyoto Katsura Hospital, Yamada-hirao-cho 17, Nishikyo-ku, Kyoto 615-8256, Japan.

Received: 9 July 2020 Accepted: 20 January 2021

Published online: 10 February 2021

\section{References}

1. National Institute for Health and Care Excellence. Hip fracture: management 2011. London: National Institute for Health and Care Excellence; 2011.

2. van der Sijp MPL, van Delft D, Krijnen P, Niggebrugge AHP, Schipper IB. Surgical approaches and hemiarthroplasty outcomes for femoral neck fractures: A meta-Analysis. J Arthroplast. 2018:33:1617-27 e9.

3. Oe K, lida H, Kobayashi F, Ueda N, Nakamura T, Okamoto N, Saito T. Reattachment of an osteotomized greater trochanter in total hip arthroplasty using an ultra-high molecular weight polyethylene fiber cable. J Orthop Sci. 2018;23(6):992-9.

4. Kuroda Y, Akiyama H, Nankaku M, So K, Matsuda S. Modified Mostard approach with ultra-high-molecular-weight polyethylene tape for total hip arthroplasty provides a good rate of union of osteotomized fragments. J Orthop Sci. 2015;20(4):633-41.

5. Dall D. Exposure of the hip by anterior osteotomy of the greater trochanter. A modified anterolateral approach. J Bone Joint Surg Br. 1986;68(3):382-6.

6. Fujita M, Diab M, Xu Z, Puttlitz CM. A biomechanical analysis of sublaminar and subtransverse process fixation using metal wires and polyethylene cables. Spine (Phila Pa 1976). 2006;31(19):2202-8.

7. Takahata M, Ito M, Abumi K, Kotani Y, Sudo H, Ohshima S, Minami A. Comparison of novel ultra-high molecular weight polyethylene tape versus conventional metal wire for sublaminar segmental fixation in the treatment of adolescent idiopathic scoliosis. J Spinal Disord Tech. 2007;20(6):449-55.

8. Iwase T, Morita D, Takemoto G. The effects of patient characteristics and stem alignment on distal femoral cortical hypertrophy after cemented polished tapered stem implantation. Eur J Orthop Surg Traumatol. 2019: 30(4):559-67.

9. Fujita H, Hara H, Harada H, Kataoka M, Tominaga T, Nishimura R. Prospective, comparative study of cemented, smooth-surfaced titanium stems and polish-surfaced, stainless steel stems at a minimum follow-up of 10 years. Eur J Orthop Surg Traumatol. 2020;30(3):501-12.

10. Oonishi H, Kadoya Y, Iwaki H, Kin N. Total hip arthroplasty with a modified cementing technique using hydroxyapatite granules. J Arthroplast. 2001; 16(6):784-9.

11. Oonishi H, Ohashi H, Oonishi H Jr, Kim SC. THA with hydroxyapatite granules at cement-bone interface: 15- to 20-year results. Clin Orthop Relat Res. 2008:466(2):373-9.

12. Fujita H, Oonishi H. Ito, Kim SC, Doukawa H. radiological evaluation of the femoral component fixed with interface bioactive bone cement (IBBC) in revision THA. J Arthroplast. 2008;23(5):689-93.

13. Robertson GA, Wood AM. Hip hemi-arthroplasty for neck of femur fracture: what is the current evidence? World J Orthop. 2018;9(11):235-44.

\section{Publisher's Note}

Springer Nature remains neutral with regard to jurisdictional claims in published maps and institutional affiliations.

Ready to submit your research? Choose BMC and benefit from:

- fast, convenient online submission

- thorough peer review by experienced researchers in your field

- rapid publication on acceptance

- support for research data, including large and complex data types

- gold Open Access which fosters wider collaboration and increased citations

- maximum visibility for your research: over $100 \mathrm{M}$ website views per year

At BMC, research is always in progress.

Learn more biomedcentral.com/submissions 